\title{
LIVELIHOOD EMPOWERMENT AGAINST POVERTY IN THE UPPER WEST REGION, GHANA: THE DEFIES AND GRIEVANCE REDRESS MECHANISM
}

\author{
Fuseini, M. N. \\ Department of Business Administration, BlueCrest College, Accra, Ghana
}

moses.fuseini@bluecrest.edu.gh

\begin{abstract}
Livelihood Empowerment Against Poverty (LEAP) is a social assistance initiative that aims to help people living in poverty and the needy change their condition. However, few studies have focused exclusively on defies and the grievance redress mechanism (GRM) associated with LEAP's activities. GRM and LEAP defies are essential because they have the potential to reduce LEAP programme impacts. To this end, concurrent mixed methods was applied to study defies and GRM of LEAP. A total of 302 LEAP beneficiaries took part in the study. Data were gathered using a questionnaire and an interview guide. Chi-square, descriptive statistics, and thematic analysis were used to analyse the data. The major defies of LEAP that were discovered were related to beneficiary and administrative problems. Although GRM existed, it proved to be ineffective. Appropriate support and supportive programmes must be assured to ensure full benefits for beneficiaries, while defies under recourse must be dealt with quickly.
\end{abstract}

\section{Keywords: Social Assistance, Social Cash Transfer, Defies, Grievance Redress Mechanism, Ghana}

\section{Introduction}

Globally, the incidence of poverty remains high, and as such, goal one of the Sustainable Development Goals [SDGs] focuses on reducing poverty (United Nations [UN], 2016, 2018). Earlier, the International Labour Organization [ILO] (2017) had argued that social protection is prime to achieving SDG one. Its theoretical grounding is from the entitlement theory, which argues that pull and response failures reduce the capacity of people living in poverty to provide for their needs; thus, they require external assistance to transition out of poverty (Sen, 1986). Among the variants of social protection pathways to tackling poverty is social assistance. Non-contributory allocations bequeathed as cash and non-cash to the needy and poor constitute social assistance (Debrah, 2013). Since in-kind transfers were alleged to cause market distortions in the 1990s, social cash transfers (SCT) became famous as a means of alleviating poverty (Tabor, 2002). As a result, nearly $45 \%$ of the world's population benefited from social protection cash transfers as of
2016 (UN, 2018). Cash transfers are noncontributory, dependable stipends given by state and non-state actors to the poor or disadvantaged people to improve their circumstances (Yablonski \& O'Donnell, 2009). SCT is a direct cash stipend to the poor and the needy that can be conditional or unconditional (Fiszbein et al., 2009). On the other hand, in-kind transfers are non-contributory transfers in the form of non-cash and vouchers provided to the poor and disadvantaged (Norton et al., 2001).

According to Johannsen et al. (2010), income transfers originated in Latin America and grew in popularity as a panacea for poverty reduction. Many studies (Bawelle, 2016; Fuseini et al., 2019) have shown that social assistance programmes help people get out of poverty by increasing their wages, consumption, investment in farm and non-farm businesses, and asset accumulation. Other research (Fiszbein et al., 2009; ILO, 2014) suggests little or 
no effect on poverty. The failure of social assistance programmes to consistently result in poverty reduction raises the possibility that it was due to problems associated with programme implementation.

The Livelihood Empowerment Against Poverty (LEAP) programme, which is one of Ghana's social assistance programmes, was launched in 2008 as a component of the National Social Protection Strategy aimed at people living in poverty and to accelerate human capital growth (Debrah, 2013). When LEAP was implemented in 2008, the Wa West and Wa East Districts were among the first in the Upper West Region to benefit (ILO, 2014). Currently, LEAP has spread across the entire country.

In general, empirical studies (Chiwele, 2010; Jaha \& Sika-Bright, 2015; Sackey, 2019) have found that implementing social transfers such as LEAP is difficult. These issues include a lack of government support, donor fatigue, price distortions, a meagre grant, and grant payment delays (Tabor, 2002). Yet, the missing point is that these issues are usually approached from the viewpoint of either beneficiaries or programme implementers rather than both (Jaha \& Sika-Bright, 2015; Sackey, 2019), leaving it incomplete. Furthermore, in previous research, defies were typically viewed as a side issue. Moreover, some studies have looked into the grievance redress mechanism (GRM) of social protection programmes (Barca, 2015; Barca \& Notosusanto, 2012; Rao, 2014; Samuels et al., 2013; World Bank, 2014), but none has looked into LEAP. In this context, this research focuses on the defies and GRM of LEAP in the Upper West Region.

\section{Literature Review}

\section{Defies of Social Assistance Programmes}

Defies in social assistance programmes are recorded in the literature but often as minor issues. For example, Chiwele (2010) states that some of the challenges of Zambia's cash transfer programme include disputes over grant use, money misuse, insufficient funds to increase transfer, limited grants, administrative, infrastructural, and financial problems but ignores the GRM. Many studies in Ghana have looked at the problems associated with LEAP, but these studies have viewed the issues as minor. Joha's (2012) research in the West Mamprusi District, for example, looked at the impact of LEAP on poverty reduction. The study discovered that LEAP faced organisational challenges such as a shortage of human capital, inadequate office space, no means of transportation, no logistics, insufficient funding, irregular district implementation committee meetings, meagre and irregular transfers, and a lack of information about the programme. The GRM was not mentioned in this study. Similarly, Bawelle (2016) and Agbenyo et al. (2017) discovered that defies of LEAP were beneficiary and institutionally allied in the $\mathrm{Wa}$ West Districts and Wa Municipality. Nonetheless, because the emphasis of these studies was on the impact of LEAP on poverty, the defies were viewed as a side issue.

However, the studies of Jaha and Sika-Bright (2015) and Sackey (2019) were distinct in that they focused primarily on defies. In particular, Jaha and Sika-Bright's (2015) study looked at the institutional challenges of LEAP in the Upper West Region. The sample size was nine respondents, with each district's LEAP programme officers making up the sample. According to Jaha and SikaBright (2015), LEAP faces three significant challenges, which include administrative, beneficiary, and political challenges. Nonetheless, neither Jaha and Sika-Bright (2015) nor Sackey (2019) found any evidence of GRM.

\section{Grievance Redress Mechanism (GRM)}

GRM is the channel through which people can express their dissatisfaction with service delivery and request a remedy (Ringold et al., 2012). When complaints cannot be addressed at the point of delivery, GRM becomes useful (Ringold et al., 2012). Non-payment of grants, overdue payments, travelling to receive grants, or paying someone to pick up grants, as in the case of SCTs in Colombia, are common complaints (Restrepo, 2011). Nonetheless, according to the National Audit Office (2008), only a tiny percentage of the population in Europe uses GRMs in either autonomous redress organisations or government 
agencies and programmes. In Ringold et al.'s (2012) study of Argentina's Plan Jefes y Jefas de Hogar Desocupados and Mexico's Oportunidades, they found low-income families and females were less likely than others to have access to GRMs. Lack of understanding, fear of retaliation, the feeling that nothing would change due to the appeal, insufficient knowledge of the GRM, and the time and cost involved in filing an appeal were all factors that hampered the use of GRM (National Audit Office, 2008). As a result, there is a controversy about the efficacy of GRM; although the World Bank (2014) and Rao (2014) believe it is effective in the Philippines and Pakistan, others, such as Barrett (2008) and Samuels et al. (2013) believe it is not effective in Kenya and Palestine.

\section{Methodology}

\section{Study Setting}

The Wa East and Wa West Districts in the Upper West Region were chosen as the study's areas because they were among the first districts to adopt the LEAP scheme. They were also selected because they have the highest poverty rates in the area and country, with $92 \%$ and $84 \%$, respectively, in the Wa West and Wa East Districts. As a result, LEAP was founded in 2008 as a tool to alleviate poverty (Ghana Statistical Service [GSS], 2015; ILO, 2014). For LEAP beneficiaries to get the most out of the programme, an efficient GRM must be in place to minimise defies.

\section{Research Design}

The research approach used was a mixed-methods design. Mixed methods design combines qualitative and quantitative research techniques in a single study to better understand the topic at hand (Creswell, 2003). This approach allowed data to be collected from LEAP participants and key informants. Concurrent mixed methods design was the specific variant of mixed methods design used. This design allowed for the simultaneous collection of quantitative and qualitative data on the challenges faced by LEAP beneficiaries and implementers and the GRM.

\section{Sampling Design}

The sample size was statistically determined using the formula: $\mathrm{n}=\mathrm{N} /\left[1+\mathrm{N}(\mathrm{e})^{2}\right]$ where " $\mathrm{n}$ " is the sample size, " $\mathrm{N}$ " is the population size, and " $\mathrm{e}$ " is the confidence level. Thus, it was determined as follows: $\mathrm{n}=1230 /\left[1+1230(0.05)^{2}\right]$ which generates a sample size of 302. The LEAP recipients were chosen from a sampling frame of 1230 people using stratified random sampling (constituting older people living in poverty, caregivers of orphans and vulnerable children [COVC], and persons with extreme disability [PWD]). The sampling frame was collected from the Wa West and Wa East Districts' Department of Social Welfare and Community Development district offices. Since the population was diverse, it was stratified by LEAP beneficiary category to ensure that all of the beneficiary groups were included in the study. The sample was distributed in a balanced manner (Table 1). Eight key informants were chosen. They were made up of four members from the Community LEAP Implementation Committee (CLIC), two from each district, and four members from the District LEAP Implementation Committee (DLIC), two from each district, who were chosen by purposive sampling. The key informants were chosen using purposeful sampling because they are the LEAP implementers and were believed to have in-depth knowledge of the defies and the GRM. 
Table 1: Sample Distribution of LEAP Beneficiaries

\begin{tabular}{lcccccc}
\hline Beneficiary Category & \multicolumn{3}{c}{ Population } & & \multicolumn{3}{c}{ Sample } \\
& Wa West & Wa East & Total & Wa West & Wa East & Total \\
& District & District & & District & District & \\
& 216 & 138 & 354 & 53 & 34 & 87 \\
\hline COVC & 379 & 187 & 566 & 93 & 46 & 139 \\
$\begin{array}{l}\text { Older people living in } \\
\text { poverty }\end{array}$ & 171 & 139 & 310 & 42 & 34 & 76 \\
PWD & 766 & 464 & 1230 & 188 & 114 & 302 \\
\hline Total & 76 & & & & & \\
\hline
\end{tabular}

\section{Instruments, Data Collection and Analysis}

The tools used to gather quantitative and qualitative data were a questionnaire and an interview guide. The LEAP beneficiaries were given a questionnaire that included both closed and open-ended questions. Samples of the closed-ended questions included: Did you face any difficulties? Are you familiar with LEAP GRM? Have you used LEAP GRM before? What was the LEAP GRM's effectiveness? Some examples of the open-ended questions included: What obstacles do you face as a LEAP beneficiary? What is the best way to explain LEAP GRM? What happened when you used the GRM? For the interview guide, it covered open-ended but structured questions. The issues on this instrument elicited responses from the key informants. During the interviews, participants were probed about the following topics: What challenges do LEAP beneficiaries face? What challenges do you face as LEAP implementers? Are the LEAP recipients conscious of a GRM?

From the 1st to 30th June 2019, data was collected from beneficiaries and key informants. After permission was given, enumerators collected data from respondents while the researcher performed key informant interviews using a recorder. The quantitative data were entered into SPSS Version 24 and analysed using the chi-square test of independence, cross-tabulation, and descriptive statistics. Thematic analysis was used to examine the qualitative data. The data was first transcribed and then a manual method was used to distinguish codes and patterns from the data collected using an inductive approach. Where applicable, the identified themes were used to support the quantitative findings or were handled as separate issues.

\section{Results and Discussion}

\section{Defies in the LEAP Scheme}

The existence of any obstacles in a programme that has yet to be implemented or is still being implemented can reduce the programme's potential impacts on potential or current beneficiaries. As a result, the focus of this section is on determining whether or not defies were encountered during the process of LEAP, and the particular challenges that were encountered.

On "whether or not LEAP beneficiaries face challenges", the findings showed that $55 \%$ of the 302 respondents did not face any challenges, while the remaining (45\%) did. As a result, the likelihood of LEAP having a positive impact on beneficiaries' living conditions would be reduced. Similarly, the key informants acknowledged that they often ran into issues when attempting to fulfil their roles as LEAP implementers. This supports Chiwele (2010) and Jaha and Sika-Bright's (2015) findings that Zambia's social assistance programme and Ghana's LEAP scheme are generally problem-laden.

When the difficulties in LEAP were broken down by respondent category, it was discovered that the majority of COVC (51\%) and older people living in 
poverty $(63 \%)$ said they had not encountered any defies (Table 2). On the contrary, most PWD (55\%) said they faced difficulties as LEAP recipients. A chi-square test was also used to see whether there was a statistically significant difference in the beneficiaries' challenges. At the 5\% level, the differences were statistically significant $\left(\chi^{2}=\right.$ $7.799 ; \mathrm{df}=2 ; \mathrm{p}$-value $=0.020)$, indicating that there are differences among the beneficiaries regarding difficulties. Because of the challenges they face, PWDs are less likely to benefit from LEAP ultimately.

Table 2: Beneficiary Category by Challenges in the LEAP Programme

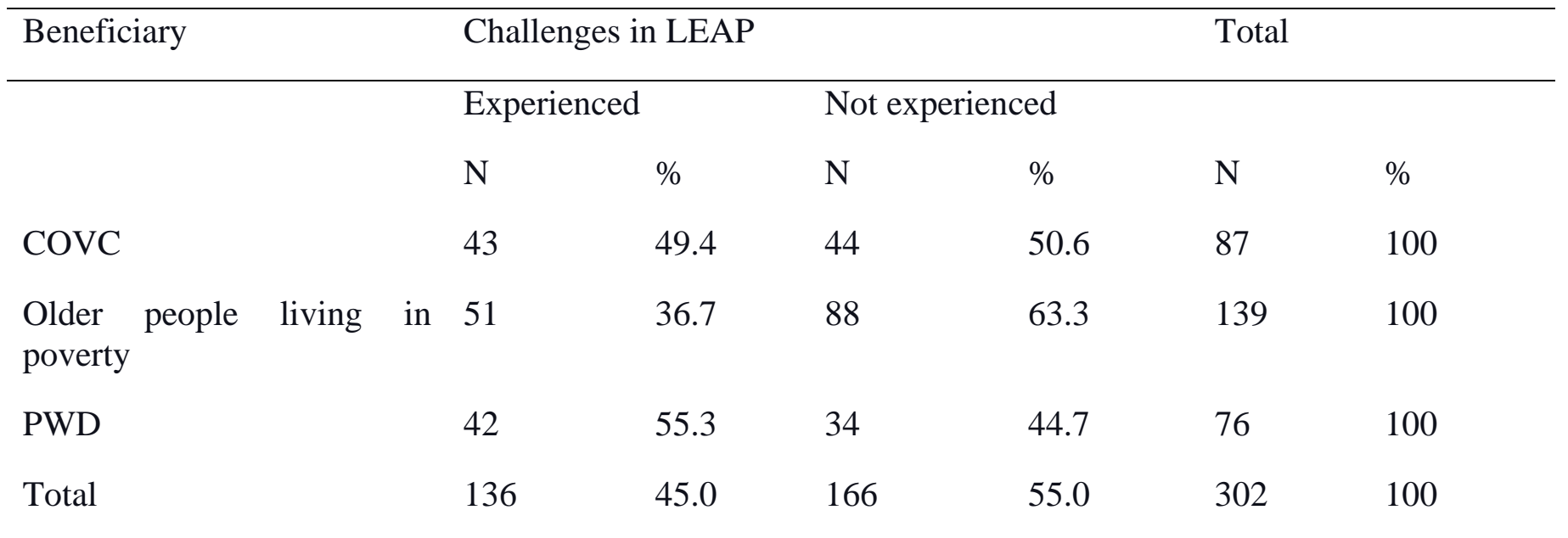

Note: $\chi^{2}=7.799 ; \mathrm{df}=2 ; p$-value $=0.020 ; \alpha=0.05$

The main themes that arose from the LEAP defies centred on the beneficiary and related administrative difficulties. One of the types of problems associated with the LEAP scheme is beneficiary-related defies. Beneficiaries faced a variety of challenges, according to interviews with beneficiaries and key informants. Distance to payment centres, cash-related problems, disagreement over the use of a cash grant, and insufficient complementary services were among the challenges. A typical instance was "LEAP beneficiaries complain that they have to travel long distances to receive their grant, which they are unhappy about because they have to spend money on transportation," said a key informant from the Wa West District (18th June 2019). This is in line with Jaha and Sika-Bright's (2015) findings that LEAP recipients complain about having to travel long distances to receive their cash grant.

Aside from complaining about long distances, the beneficiaries disclosed that they face other financial difficulties. They complained that the cash grant is insufficient, that it is often overdue, and that it does not appear on their e-zwich cards at other times. Some of the recipients found the small cash grant they received to be a big issue. They complained that the amount was insufficient to meet their basic requirements. The key informants confessed to receiving complaints from some beneficiaries about the sum they got due to this. For example, a key informant stated that "some of the LEAP program recipients, when they come to receive their cash grant, usually complain that it is too insufficient to meet all of their basic needs" (Key informant from the Wa West District, 18th June 2019). This indicates that the cash grant was deemed insufficient. The concerns about the small cash grant are consistent with findings by Joha (2012), who found that recipients of social assistance programs in the West Mamprusi District complain about the small grant amounts. This indicates that beneficiaries consider the inadequacy of the cash grant to be an issue. This is, however, necessary because it avoids reliance on the grant.

Furthermore, the respondents admit to having issues with the scheme, citing delays in the payment 
of the LEAP cash grant. According to key informants, this situation is caused by three factors: the Ministry of Gender, Children and Social Protection (MoGCSP) not releasing funds for payment, beneficiaries' grants not reflecting in their e-zwich accounts, and delays from participating payment banks. Any one of these, or a combination of them, causes beneficiaries' payments to be delayed. This has an impact on beneficiaries' ability to meet their needs. "Delays in payment of cash grants to beneficiaries are usually due to delays from the participating paying bank or the ministry failing to release money on time for the payments," according to a key informant from Wa East District (9th June 2019). From this submission, it is clear that the delays in payment of cash transactions are continuing. This backs up the results of Jaha and Sika-Bright (2015) and Bawelle (2016), who found that LEAP recipients in the Upper West Region complain about payment delays.

In another case, interviews with respondents and key informants showed that support services were not adequately provided. According to some of the respondents, this has reduced the benefits they expected from the LEAP program. Since the provision of these items and services is uncertain, key informants noted that there is no guarantee that beneficiaries would receive free school uniforms, sandals, exercise books, school feeding, skills training, and labour-intensive public works. For instance, a key informant from the Wa West District (18th June 2019) stated that "the provision of in-kind services to beneficiaries was unreliable. This was due to the fact that, as partners, we had no power over their provision." This indicates that the additional cushioning that beneficiaries required from complementary services were largely unavailable. Similarly, Jaha and Sika-Bright (2015) discovered that the LEAP scheme's beneficiaries are not receiving sufficient complementary services.

On the other hand, the administrative defies present a new collection of issues that obstruct the LEAP program's daily operations in various districts. Inadequate office facilities, non-payment of salaries, limited meeting of DLIC and CLIC representatives, inadequate transportation, a misunderstanding of targeting, and political interferences are among the administrative defies that have surfaced. In this regard, a key informant stated:

Usually, I am not stimulated to work when I come to the office. This is because the furniture is in poor condition. Furthermore, we do not have enough computers to carry out our responsibilities. This causes me to work at a slower pace than expected. We are not paid our allowance either, but I believe we are entitled to it because we provide services. Moreover, we do not have any secure transportation to track LEAP's activities (Key informant from the Wa East District, 9th June 2019).

Poorly furnished offices, lack of transportation, and limited meetings of implementers were some of the defies of social assistance schemes in Zambia and Ghana, according to Chiwele (2010) and Jaha and Sika-Bright (2015).

According to key informants, political involvement in LEAP happens while recipients are being enrolled, when assembly members attempt to leverage their political clout to advocate for the inclusion of groups within their catchment areas, as well as for specific individuals within these communities. They did not realise that the beneficiary community's selection is based on the district's poverty mapping, which the GSS usually does. They say that when assembly members learn that their electoral areas and the people they lobbied for were not chosen, they blame the district's LEAP implementation team. A key informant defined a typical case as follows:

Hmmm! When I give presentations about the LEAP initiative during assembly meetings, some assembly members usually come to me and demand that their communities be included, claiming that they have been discriminated against because their communities often have people living in poverty. Some assembly members also advocate for their neighbourhoods to be enrolled in LEAP through the District Chief Executive. This puts undue strain on me as I carry out my responsibilities (Key 
informant from the Wa West District, 18th June 2019).

According to the key informant's submission, interfering with the activities of LEAP scheme implementers in the districts is an activity that jeopardises a healthy work environment. Because of this condition, inclusion errors occur. As a result, those who are not supposed to profit are now benefiting, while those who need the stipend might be left out (i.e., exclusion errors). This is in line with the findings of Jaha and Sika-Bright (2015) and Agbenyo et al. (2017), who found that politicians in the Upper West Region affected beneficiary group selection, resulting in weak targeting.

\section{LEAP Grievance Redress Mechanism (GRM)}

Since defies encountered in the LEAP program can reduce the scheme's value to beneficiaries, it was critical to determine if beneficiaries were aware of any remedy mechanisms and their efficacy. The survey results on respondents' knowledge of the availability of a GRM revealed that $65 \%$ of the 302 respondents were aware of the GRM's availability. In Palestine, Hamad and Pavanello (2012) found that most recipients of the social assistance programme were aware of the framework for reporting challenges. According to the findings of the key informant interviews, several key informants notify beneficiaries about the channels for communicating problems they face.

"I told beneficiaries that there is a mechanism for reporting problems and that through the same mechanism, they will get their feedback on the status of the problems they send," said a key informant from Wa East District (9th June 2019).

This suggests that the key informants' activities have aided in raising beneficiary consciousness of the redress process' existence.

Furthermore, respondents' knowledge of the existence of a GRM for reporting problems encountered was broken down based on whether or not they had encountered a problem. The findings (Table 3) revealed that half $(50 \%)$ of the 136 respondents who witnessed defies in LEAP believed there was a GRM, while the other half (50\%) disagreed. This supports Hamad and Pavanello's (2012) findings that beneficiaries of the Palestinian National Cash Transfer Program who faced obstacles were not always aware of the availability of a GRM.

Table 3: Awareness of GRM by Problems Encountered

\begin{tabular}{|c|c|c|c|c|c|c|}
\hline \multirow[t]{3}{*}{ Awareness of GRM } & \multicolumn{4}{|c|}{ Problems in the LEAP Programme } & \multicolumn{2}{|c|}{ Total } \\
\hline & \multicolumn{2}{|c|}{ Experienced } & \multicolumn{2}{|c|}{ Not Experienced } & \multirow[b]{2}{*}{$\mathrm{N}$} & \multirow[b]{2}{*}{$\%$} \\
\hline & $\mathrm{N}$ & $\%$ & $\mathrm{~N}$ & $\%$ & & \\
\hline Aware & 68 & 50.0 & 127 & 76.5 & 195 & 64.6 \\
\hline Not aware & 68 & 50.0 & 39 & 23.5 & 107 & 35.4 \\
\hline Total & 136 & 100 & 166 & 100 & 302 & 100 \\
\hline
\end{tabular}

Note: $\chi^{2}=21.814 ; \mathrm{df}=1 ; p$-value $=0.000 ; \alpha=0.05$

However, about $77 \%$ of the 166 respondents who said that they had no issues with the LEAP scheme were aware of the existence of a reporting system for problems encountered. This means that if they run into any issues, they will use the reporting system, as they are aware of its presence. According to Innovative Development Strategies (2013), most
Benazir Income Support Program beneficiaries in Pakistan who did not face difficulties were aware of the presence of a GRM that they could use if required. A chi-square test of independence was used to see whether there was a gap in understanding the availability of a GRM between those who had issues and those who did not. The 
test results were statistically significant at the 5\% level $\left(\chi^{2}=21.814 ; \mathrm{df}=1 ; \mathrm{p}\right.$-value $\left.=0.000\right)$, indicating a discrepancy in perception of the existence of a GRM. Those who did not have any issues were more likely (77\%) to be conscious of the GRM than those who did.

Those who said they were aware of the GRM's availability spelt out the mechanism. They clarified that if a problem arose, they were required to notify a CLIC member. The CLIC member then reports it to the district social welfare and community development officer, who then reports it to the Department of Social Welfare and Community Development's LEAP case management unit. Similarly, the key informants outlined the procedure for documenting issues experienced by LEAP recipients (Figure 1). According to the key informants, the CLIC member can submit the case to the DLIC member or District Social Welfare and Community Development Officer for referral to the Case Management Unit at the headquarters. In a reverse way, feedback on actions taken on a recorded case goes through the same channel (Figure 1).

\section{Figure 1: GRM for LEAP}

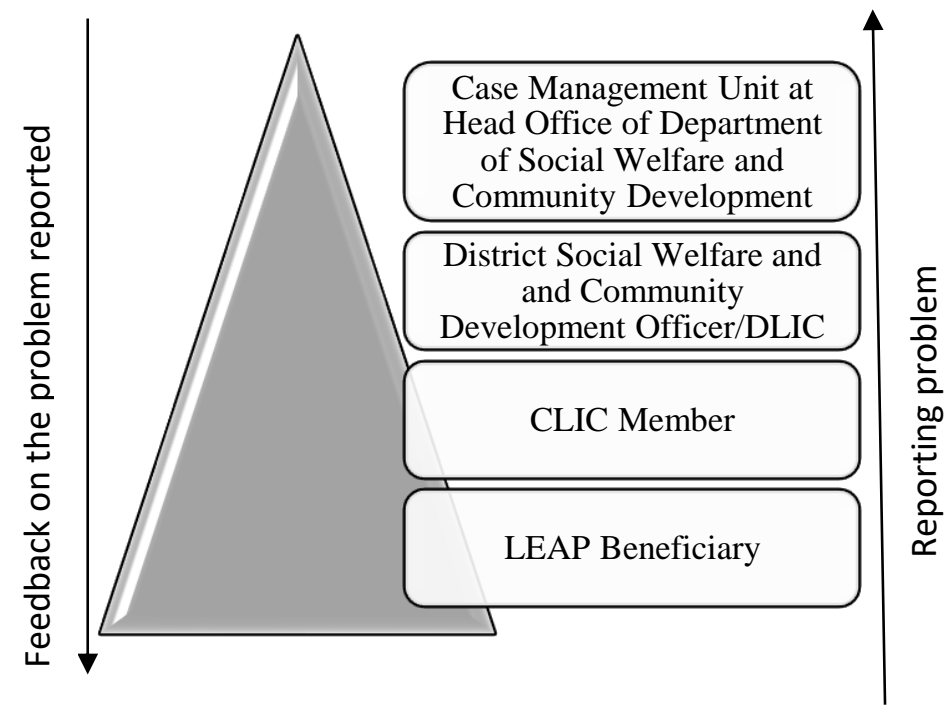

\section{Source: Author's Construct (2019)}

In addition, the respondents' use of the GRM was investigated. According to the findings, $81 \%$ of the 68 respondents who said they had problems with the LEAP scheme and were aware of the GRM admitted to reporting their issues, while the rest did not. When faced with defies, key informants revealed that some LEAP beneficiaries used the GRM. This backs up the results of Innovative Development Strategies (2013), which found that Benazir Income Support Programme beneficiaries used the GRM to solve problems.

The efficacy of LEAP's GRM was assessed. The majority $(67 \%)$ of the 55 respondents who used the GRM said it was ineffective, while the rest said it was successful. When they reported their concerns to the CLIC member, some said nothing happened, while others said they got feedback that they were still working to fix the issues. However, some people said they were told there was nothing they could do about the problems. This indicated that the GRM was of little use to the beneficiaries. Many who did not use the GRM said they did not use it because they would not be heard, they did not trust CLIC, and did not feel like reporting. After all, they will not profit ultimately from LEAP because their problems are not registered for resolution. Hamad and Pavanello (2012) made related findings that the Palestinian National Cash Transfer Programme beneficiaries were unable to use the GRM when they encountered difficulties because they did not trust the system.

\section{Conclusions and Policy Implications}

Overall, LEAP is fraught with issues, as some beneficiaries and implementers alike have run into defies that can restrict the programme's benefits. PWDs, in particular, were more susceptible to defies. Beneficiary and administrative problems were the most significant challenges associated with the LEAP programme. The majority of those who faced difficulties were unaware of the GRM could report their issues for remedy. Those who were aware of the GRM and who used it said it was ineffective because their expectations were not met.

As a result, the MoGCSP must ensure that LEAP receives sufficient funding. This will ensure that the funds for stipend payments are released immediately for each period. It will also ensure that the stipend can be increased regularly to meet the beneficiaries' basic needs and enable them to invest in income-generating projects to help them achieve 
self-sufficiency. Beneficiaries can no longer worry about the expense of traveling to receive the stipend because the stipend is so generous. DLIC and CLIC will receive their fair share of funds to carry out their mandate as LEAP implementers if sufficient funds are available. In addition, beneficiaries' access to additional programmes must be ensured. MoGCSP must sign memoranda of understanding with service providers to accomplish this. This will ensure that they are committed to providing their services to LEAP beneficiaries and when they are needed. This is essential to provide additional security to the beneficiaries.

There is also a need to sensitise LEAP beneficiaries about the GRM. This is important because many of those who faced difficulties were unaware of the system's existence. As a result, LEAP recipients would need to be educated on GRM to use it as needed. This process of sensitisation should be ongoing. Furthermore, when beneficiaries announce a case, it must be handled as a matter of urgency. The beneficiaries would gain confidence in the GRM because of this. Finally, to resolve the problem of targeting anomalies in the form of inclusion errors, beneficiaries should be chosen based on data from the Ghana National Household Registry, a database of the poor and vulnerable. Only eligible individuals will be targeted because of this.

\section{References}

Agbaam, C. \& Dinbabo, M. F. (2014). Social grants and poverty reduction at the household level: Empirical evidence from Ghana. $J$ Soc Sci, 39(3): 293-302.

Agbenyo, F., Galaa, S. Z. \& Abiiro, G. A. (2017). Challenges of the targeting approach to social protection: An assessment of the Ghana Livelihood Empowerment against Poverty Programme in the Wa Municipality of Ghana. Ghana Journal of Development Studies, $14(1)$ : 19-38. https://doi.org/10.4314/gjds.v14i1.2

Barca, V. (2015). Grievance mechanisms for social protection programmes: Stumbling blocks and best practice (One-Pager 320). The
International Policy Centre for Inclusive Growth. $\quad$ https://socialprotectionhumanrights.org/wp-content/ uploads/2016/04/OP320_Grievance_mecha nisms_for_social_protection_programmes stumbling_blocks_and_best_practice.pdf. Accessed: 10th May 2021.

Barca, V., \& Notosusanto, S. (2012). Review of, and recommendations for, grievance mechanisms for social protection programmes (final report summary). Oxford Policy Management. https://www.opml.co.uk/files/Publications/ 7748-indonesia-grievances/grievancesexec-summary-final.pdf?noredirect $=1$. Accessed: 10th May 2021.

Barrett, S. (2008). Achieving accountability in cash transfer programmes: The case of the social protection rights component of the Kenya Hunger Safety Net Programme. International Social Protection Conference, $8-10 \quad$ September 2008. http://www.kulima.com/wordpress/wpcont ent/upl oads/2011/03/Co nferenceproceedings.pdf\#page $=140$. Accessed: 14 th May 2019.

Bawelle, E. B. G. (2016). Impact of Livelihood Empowerment against Poverty programme in Ghana: The case of Wa West District. International Journal of Social Science Research, 4(2): 24-43.

Chiwele, D. K. (2010). Assessing administrative capacity and costs of cash transfer schemes in Zambia implications for rollout. International Policy Centre for Inclusive Growth.

Creswell, J. W. (2003). Research design: Qualitative, quantitative and mixed methods approaches (2nd ed.). SAGE Publications.

Debrah, E. (2013). Alleviating poverty in Ghana: The case of Livelihood Empowerment against Poverty (LEAP). Africa Today, 59(4): 41-67. 
Fiszbein, A., Schady, N., Ferreira, F. H. G., Grosh, M., Keleher, N., Olinto, P. \& Skoufi, E. (2009). Conditional cash transfers: Reducing present and future poverty (World Bank Policy Research Report No. 47603). Washington DC: The International Bank for Reconstruction and Development / World Bank.

Fuseini, M. N., Enu-Kwesi, F. \& Sulemana, M. (2019). Poverty reduction in Upper West Region, Ghana: role of the Livelihood Empowerment Against Poverty programme. Development in Practice, 29(6): 760-773.

Ghana Statistical Service (GSS). (2015). Ghana poverty mapping report. GSS: Accra.

Hamad, B. A. \& Pavanello, S. (2012). Transforming cash transfers: Beneficiary and community perspectives on the Palestinian National Cash Transfer Programme- Part 1- The case of the Gaza Strip. Overseas Development Institute.

Innovative Development Strategies. (2013). Scorecard spot check evaluation: Benazir Income Support Programme [BISP] (Payments Spot Check Phase 4 Report). http://bisp.gov.pk/wp-content /uploads/2016/10/Targeting-Survey-SpotCheck-Final-Report.pdf. Accessed: 14th May 2019.

International Labour Organization (ILO). (2014). Rationalizing social protection expenditure in Ghana. ILO.

International Labour Organization (ILO). (2017). World Social Protection Report 2017-19: Universal social protection to achieve the Sustainable Development Goals. ILO.

Jaha, I. R. \& Sika-Bright, S. (2015). Challenges of the Livelihood Empowerment Against Poverty Programme in the Upper West Region of Ghana: The institutional perspective. UDS International Journal of Development [UDSIJD], 2 (1): 188-205.
Joha, B. I. (2012). Effects of livelihood empowerment programme in reducing poverty of beneficiary households in Yama, Northern Region [Master's Thesis]. University of Ghana, Ghana.

Johannsen, J., Tejerina, L. \& Glassman, A. (2010). Conditional cash transfers in Latin America: Problems and opportunities. In S.W. Handayani (Ed.), Social assistance and conditional cash transfers (pp. 139177). Asian Development Bank.

National Audit Office. (2008). Feeding Back? Learning from Complaints Handling in Health and Social Care (HC 853 Session 2007-2008). https://www.nao.org.uk/wpcontent/uploads/2008/10/0708853.pdf. Accessed: 14th May 2019.

Norton, A., Conway, T. \& Foster, M. (2001). Social protection concepts and approaches: Implications for policy and practice in international development (Working Paper No. 143). Overseas Development Institute (ODI).

Rao, S. (2014). Capacity building for social protection. GSDRC Helpdesk Research Report 1168. GSDRC, University of Birmingham.

Restrepo, S. R. (2011). Orígenes de la Facultad de Derecho de la Universidad de los Andes vistos por un fundador. Revista de Derecho Privado, (46): 1-7.

Ringold, D., Holla, A., Koziol, M., \& Srinivasan, S. (2012). Citizens and service delivery: assessing the use of social accountability approaches in human development sectors. The World Bank.

Sackey, P. (2019). Ghana's Livelihood Empowerment Against Poverty (LEAP) programme is leaking: Irregularities watering down the impact of the flagship LEAP programme. Cogent Social Sciences, 5(1): 1-11. 
Samuels, F., Jones, N. \& Malachowska, A. (2013). Holding cash transfers to account: Beneficiary and community perspectives. Overseas Development Institute (ODI).

Sen, A. (1986). Food, economics and entitlements (WILDER Working Paper No. 1). World Institute for Development Economics Research (WILDER), United Nations University.

https://www.wider.unu.edu/sites/default/fil es/WP1.pdf. Accessed: 14th May 2019.

Tabor, S. R. (2002). Assisting the poor with cash: Design and implementation of social transfer programs (Social Protection Discussion Paper Series No. 0223). World Bank.

United Nations. (2016). Global sustainable development report 2016. UN Department of Economic and Social Affairs.

United Nations. (2018). Promoting inclusion through social protection: Report on the world Social situation 2018. https://www.un.org/development/desa/dspd /wp-content/uploads/sites/ 22/2018/06/rwss2018-full-advancedcopy.pdf. Accessed: 14th May 2019.

World Bank. (2014). Grievance redress system of the conditional cash transfer program in the Philippines (Case Study 90178). Social Development Department \& East Asia Social Protection Unit. http://wwwwds.worldbank.org/external/default/WDSC ontentServer/WDSP/IB/2014/08/27/00044 2464_20140827144857/Rendered/PDF/90 1780BRI0P14600Philippines0Final02.pdf. Accessed: 14th May 2019.

Yablonski, J., \& O'Donnell, M. (2009). Lasting benefits: The role of cash transfers in tackling child mortality. Save the Children Fund. 